\title{
Loss of SOCS3 in myeloid cells prolongs survival in a syngeneic model of glioma
}

\author{
Braden C. McFarland ${ }^{1}$, Margaret P. Marks ${ }^{1}$, Amber L. Rowse ${ }^{1}$, Samuel C. Fehling ${ }^{1}$, \\ Magda Gerigk ${ }^{1}$, Hongwei Qin ${ }^{1}$, Etty N. Benveniste ${ }^{1}$ \\ ${ }^{1}$ Department of Cell, Developmental and Integrative Biology, University of Alabama at Birmingham, Birmingham, AL, USA \\ Correspondence to: Braden C. McFarland, e-mail: bdcox@uab.edu
}

Keywords: SOCS3, glioblastoma, JAK/STAT, macrophage, GL261

Received: September 14, 2016

Accepted: February 16, 2016

Published: March 08, 2016

\section{ABSTRACT}

In glioma, microglia and macrophages are the largest population of tumorinfiltrating cells, referred to as glioma associated macrophages (GAMs). Herein, we sought to determine the role of Suppressor of Cytokine Signaling 3 (SOCS3), a negative regulator of Signal Transducer and Activator of Transcription 3 (STAT3), in GAM functionality in glioma. We utilized a conditional model in which SOCS3 deletion is restricted to the myeloid cell population. We found that SOCS3-deficient bone marrow-derived macrophages display enhanced and prolonged expression of proinflammatory M1 cytokines when exposed to glioma tumor cell conditioned medium in vitro. Moreover, we found that deletion of SOCS3 in the myeloid cell population delays intracranial tumor growth and increases survival of mice bearing orthotopic glioma tumors in vivo. Although intracranial tumors from mice with SOCS3-deficient myeloid cells appear histologically similar to control mice, we observed that loss of SOCS3 in myeloid cells results in decreased M2 polarized macrophage infiltration in the tumors. Furthermore, loss of SOCS3 in myeloid cells results in increased CD8 ${ }^{+}$T-cell and decreased regulatory $\mathrm{T}$-cell infiltration in the tumors. These findings demonstrate a beneficial effect of M1 polarized macrophages on suppressing glioma tumor growth, and highlight the importance of immune cells in the tumor microenvironment.

\section{INTRODUCTION}

On a cellular level, glioblastoma (GBM) tumors are extremely heterogeneous, consisting of resident tumor cells, tumor initiating cells, infiltrating immune cells, endothelial cells and other tumor associated stromal cells, which makes developing targeted therapies a challenge [1]. In GBM, microglia and macrophages are the largest population of tumor-infiltrating cells (5-30\% of tumor mass) and are actively recruited by the tumor via the secretion of chemo-attractants including monocyte chemoattractant protein (MCP-1, also known as CCL2), stromal-derived factor-1 (SDF-1) and macrophage-colony stimulating factor (M-CSF) [2]. Although microglia are the resident tissue macrophage of the brain, macrophages are also recruited to the tumor from peripheral hematopoietic stem cell compartments. While these two cell populations (microglia and macrophages) originate from different sites, they exhibit similar functions in GBM. Depending on the stimulus, macrophages can become polarized to an M1 (pro-inflammatory) or M2 (immunosuppressive) phenotype [3]. M1 macrophages are termed classically activated, or pro-inflammatory macrophages, and are activated in response to inflammatory stimuli including LPS, IFN- $\gamma$ and GM-CSF. M1 macrophages secrete pro-inflammatory cytokines, including TNF- $\alpha$, IL-6 and CXCL10, present antigen to immune cells and phagocytize tumor cells. M2 macrophages are termed alternatively activated, or immunosuppressive, and are activated in response to stimuli including IL-4, IL-13, and M-CSF. M2 macrophages secrete immune-suppressive cytokines such as IL-10 and TGF- $\beta$, promote $\mathrm{T}$ regulatory (Treg) cell differentiation and aid in tumor progression. However, these represent two extreme examples of M1/M2 polarization. Macrophages are often presented with multiple stimuli, especially in cancer, and the M1/M2 status should be viewed as more a continuum or spectrum [4]. In GBM, the polarization and resulting phenotype of GAMs is a bit more complicated. Overall, it has generally been accepted that upon arrival at the tumor site, macrophages become polarized to an anti-inflammatory 
M2 phenotype, and in turn aid in tumor promotion through the secretion of immunosuppressive cytokines including TGF- $\beta 1$ and IL-10, as well as the pro-angiogenic and proinvasive cytokines VEGF and MT1-MMP, respectively [2]. However, recent studies demonstrated that in several models of GBM, GAMs exhibit a mixed M1/M2 phenotype, depending on the time and stage of disease [5-9].

The Janus Kinase (JAK)/Signal Transducer and Activator of Transcription (STAT) pathway is commonly activated during inflammatory and immune responses and plays an important role in the response of myeloid cells to various stimuli [10]. Binding of a cytokine, such as IFN- $\gamma$ or IL-6, activates the receptors and in turn the associated intracellular JAK kinases become tyrosine phosphorylated. The JAKs then phosphorylate STAT transcription factors, which dimerize, translocate to the nucleus and induce gene expression [11]. There are four JAK kinases (JAK1, JAK2, JAK3, and TYK2) and a total of seven STAT transcription factors (STAT 1, 2, 3, 4, 5a, 5b, and 6) [12]. In addition to pro-survival genes, JAK/STAT activation also induces the expression of Suppressor Of Cytokine Signaling (SOCS) proteins. SOCS proteins are negative regulators of the JAK/STAT pathway, and prevent prolonged, unregulated activation of the JAK/STAT pathway [3]. Upon cytokine stimulation and subsequent SOCS expression, SOCS proteins bind to activated JAKs and to cytokine receptors via their SH2 domains, thereby suppressing signaling through this pathway. Additionally, SOCS1 and SOCS3 contain a kinase-inhibitory domain (KIR), which acts as a pseudosubstrate for JAKs and prevents further kinase activity [3].

We have generated a mouse model in which SOCS3, a negative regulator of STAT1 and STAT3, is deleted in the myeloid cell population [13, 14]. Briefly, $\mathrm{SOCS}^{\mathrm{t} / \mathrm{fl}}$ mice were crossed with LysMCre mice to generate a conditional knockout mouse that is deficient for SOCS3 in the myeloid cell population (LysMCre$\left.\mathrm{SOCS}^{\mathrm{f} / \mathrm{f}}\right)$. Deletion of SOCS3 in macrophages resulted in enhanced basal and stimulus-induced STAT1 and STAT3 activation, and corresponded with increased expression of TNF- $\alpha$, IL- 6 , iNOS, CCL2 and CXCL10 [13]. This gene expression pattern is reflective of the M1 pro-inflammatory phenotype. Interestingly, when using M2 stimuli such as IL-10 or IL-4, there was not enhanced STAT3 or STAT6 signaling, respectively, in the SOCS3deficient macrophages $[14,15]$. These data suggest that that loss of SOCS3 results in an enhanced M1 phenotype in macrophages. Additionally, in vivo studies confirmed polarization to the pro-inflammatory M1 macrophage phenotype. LysMCre-SOCS3 ${ }^{\mathrm{At} / \mathrm{fl}}$ mice exhibited enhanced inflammatory responses in models of Multiple Sclerosis and LPS-induced sepsis compared to SOCS3 $3^{\mathrm{t} / \mathrm{fl}}$ control mice $[13,14]$. Overall, these studies confirm that loss of SOCS3 in myeloid lineage cells promotes a proinflammatory M1 phenotype, and this model could be used to determine the role of M1 macrophages in additional disease states.
For this study, we have utilized the LysMCreSOCS3 $^{\mathrm{At/l}}$ M1 model in combination with the GL261 syngeneic model of glioma. The GL261 model is widely used for immunotherapeutic studies and is the most appropriate for the studies described herein [16]. Murine GL261 cells were injected into the brains of $\mathrm{SOCS}^{\mathrm{fl} / \mathrm{fl}}$ and LysMCre-SOCS3 ${ }^{\mathrm{A} / \mathrm{fl}}$ mice (termed $\mathrm{SOCS}^{--}$) in order to establish an orthotopic M1 model of glioma. We found that SOCS3-deficient bone marrow-derived macrophages (BMDM) display enhanced and prolonged expression of pro-inflammatory M1 cytokines when exposed to GL261 tumor cell conditioned medium in vitro. Moreover, we found that deletion of SOCS3 in the myeloid cell population delays intracranial tumor growth and increases survival of mice bearing orthotopic glioma tumors in vivo. We observed that loss of SOCS3 in myeloid cells results in decreased M2 polarized macrophage infiltration, increased $\mathrm{CD} 8^{+} \mathrm{T}$-cell and decreased Treg infiltration in the tumors. This study unveils a novel model of suppressing glioma tumor growth through manipulating GAM function, and highlights the importance of targeting GAMs in glioma tumors.

\section{RESULTS}

\section{Loss of SOCS3 prolongs STAT3 activation in response to GL261 tumor cell conditioned medium}

We have previously shown that macrophages deficient in SOCS3 display prolonged STAT1/STAT3 activation and increased M1 gene expression in response to LPS, IL-6 and IFN- $\gamma$ stimulation [14]. Therefore, we sought to determine the response of $\mathrm{SOCS}^{\mathrm{Ath}}$ and $\mathrm{SOCS}^{-/-}$macrophages when using GL261 conditioned medium (GCM) as the stimulus. To generate GCM, GL261 glioma cells were plated in serum free DMEM/F12 media for $24 \mathrm{~h}$ and supernatant collected. $\mathrm{BMDM}$ were isolated from $\mathrm{SOCS}^{\mathrm{t} / \mathrm{ll}}$ and $\mathrm{SOCS}^{-/-}$mice and treated with GCM (50\% volume) for various times. As shown in Figure 1A, both SOCS3 ${ }^{\mathrm{A} / \mathrm{fl}}$ and $\mathrm{SOCS}^{-/-}$ macrophages displayed STAT3 phosphorylation in response to GCM. However, $\mathrm{SOCS3}^{--}$macrophages displayed an enhanced activation at $4 \mathrm{~h}$, which remained elevated at $24 \mathrm{~h}$. This indicates that loss of SOCS3 prolongs STAT3 activation in response to GCM. STAT1 phosphorylation was enhanced in $\mathrm{SOCS}^{-/}$macrophages when exposed to GCM; however, total levels of STAT1 protein were also enhanced, and densitometric quantification reveals no elevated STAT1 activation in $\mathrm{SOCS}^{-/-}$macrophages compared to $\mathrm{SOCS}^{\mathrm{f} / \mathrm{fl}}$ cells (Supplementary Figure 1). Treatment of SOCS3 ${ }^{\text {t/lt }}$ macrophages with GCM induced mRNA expression of SOCS3 (Figure 1B). As expected, $\mathrm{SOCS3}^{--}$macrophages do not constitutively or inducibly express SOCS3, confirming the conditional deletion. Thus, treatment of $\mathrm{SOCS}^{-/-}$macrophages with GCM promotes enhanced and prolonged STAT3 activation, due to the absence of SOCS3. 


\section{GL261 cells secrete both M1 and M2 polarizing cytokines}

GBM cells secrete numerous cytokines, most of which are immunosuppressive and maintain the growth of the tumor [2]. We tested the levels of both M1 and M2 polarizing cytokines secreted by GL261 cells. Cells were plated in serum free DMEM/F12 medium for $24 \mathrm{~h}$, and supernatants were collected and analyzed by Multiplex ELISA. We found that GL261 cells secrete M1 (GM-CSF, IL-6, IFN- $\gamma$ ) and M2 (GM-CSF, IL-13, M-CSF, IL-10 and IL-4) polarizing cytokines in vitro, as well as numerous other cytokines and chemokines (Table 1). Several STAT family members are activated in response to these cytokines and are shown in Table 1. These data indicate that GL261 glioma cells secrete numerous cytokines that can polarize macrophages to the M1 and/or M2 phenotype and have the potential to activate various STAT transcription factors.

\section{$\mathrm{SOCS3}^{-/-}$macrophages display an enhanced M1 response when exposed to GCM}

M1 macrophages are characterized by an increase in pro-inflammatory gene expression [3]. BMDM from $\mathrm{SOCS}^{\mathrm{At} / \mathrm{fl}}$ and $\mathrm{SOCS}^{-/-}$mice were treated with GCM for $4 \mathrm{~h}$, and mRNA expression levels of M1 and M2 markers measured. Following treatment with GCM, SOCS3 $3^{\mathrm{t} / \mathrm{fl}}$ macrophages expressed mRNA for $T N F-\alpha, C X C L 10$ and $I L-1 \beta$ (M1 genes) by $4 \mathrm{~h}$, whereas $\mathrm{SOCS}^{-/-}$macrophages displayed significantly higher expression levels at $4 \mathrm{~h}$ (Figure 2A-2C). In addition, SOCS3 ${ }^{\mathrm{f} / \mathrm{fl}}$ macrophages expressed IL-10 and Arginase-1 (M2 genes) in response to treatment with $\mathrm{GCM}$, whereas $\mathrm{SOCS}^{-/}$macrophages displayed significantly lower levels (Figure 2D and 2E). Of note, the $\mathrm{SOCS}^{-1-}$ macrophage basal (untreated) levels of the M2 genes were lower than that of SOCS3 ${ }^{\mathrm{t} / \mathrm{fl}}$ macrophages. These findings indicate that in response to secreted tumor cytokines, macrophages that lack SOCS3 have an increased M1 response.

\section{Loss of myeloid SOCS3 prolongs in vivo survival}

Our data thus far indicate that loss of SOCS3 in macrophages results in an enhanced M1, or proinflammatory, anti-tumor phenotype when exposed to GCM. Therefore, we tested the ability of SOCS3 ${ }^{-/}$macrophages to regulate tumor growth in vivo in an intracranial model of glioma. GL261 cells were injected into the brains of $\mathrm{SOCS}^{\mathrm{H} / \mathrm{fl}}$ and $\mathrm{SOCS}^{-/-}$mice. Mice were monitored for physical signs of tumor burden and were euthanized at moribund and the brains removed for histology. SOCS3 ${ }^{-/}$ mice exhibited a significantly prolonged survival compared

A

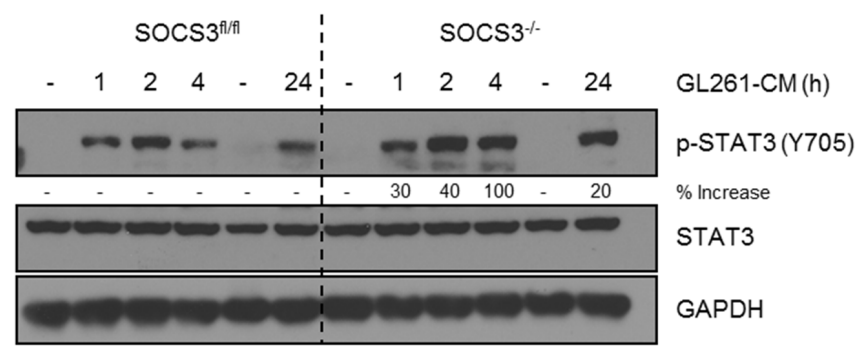

B

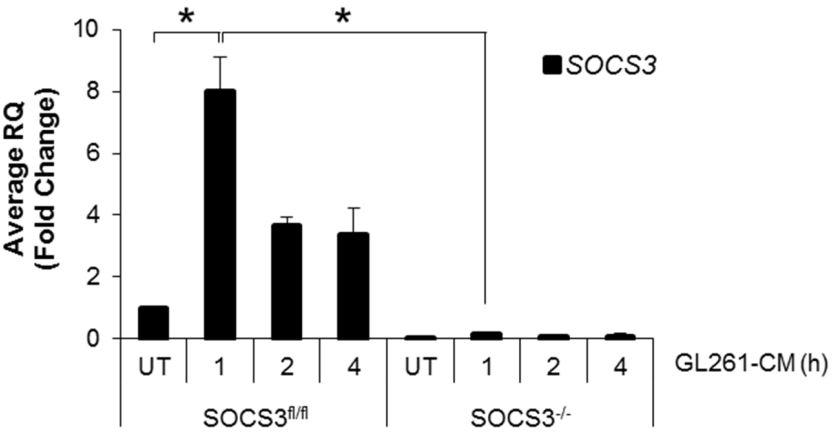

Figure 1: SOCS3-deficient macrophages exhibit prolonged activation of STAT3 when exposed to GL261 conditioned medium. (A and B) SOCS3 $3^{\mathrm{fl} / \mathrm{fl}}$ and SOCS3${ }^{-/-}$BMDM were harvested from the femurs of 7-8 week old mice and cultured in RPMI 1640 containing $10 \% \mathrm{FBS}$ and $10 \mathrm{ng} / \mathrm{ml}$ murine M-CSF for 5-7 days to expand. Cells were plated and at $24 \mathrm{~h}$ treated with GCM (50\% volume) for the indicated times. Cells were lysed and immunoblotted with the indicated Abs (A) or RNA was isolated, cDNA generated and qRTPCR performed for the indicated genes (B) Densitometric analysis is displayed as percent increase of SOCS3 ${ }^{-/}$compared to control $\mathrm{SOCS}^{\mathrm{fl} / \mathrm{fl}}$ macrophages. For example, at $1 \mathrm{~h}$ the $\mathrm{SOCS}^{-/-}$macrophages display $30 \%$ higher p-STAT3 than the corresponding SOCS3 ${ }^{\mathrm{fl} / \mathrm{fl}} 1 \mathrm{~h}$ time point. $* p<0.05$. Data are shown as mean \pm S.D. 


\section{Table 1: Multiplex ELISA of GL261 supernatants}

\begin{tabular}{|c|c|c|c|}
\hline Analyte & $\mathrm{pg} / \mathrm{ml}$ & Polarization & STAT Activation \\
\hline LIX & 2729.56 & & \\
\hline IL-1 $\alpha$ & 344.90 & & \\
\hline IL-13 & 223.44 & M2 & STAT6 \\
\hline IP-10 & 214.01 & & \\
\hline Eotaxin & 209.16 & & \\
\hline G-CSF & 172.90 & & \\
\hline IL-9 & 154.57 & & \\
\hline GM-CSF & 76.98 & $\mathrm{M} 1 / \mathrm{M} 2$ & STAT5 \\
\hline MIP-2 & 68.66 & & \\
\hline IL-15 & 64.96 & & \\
\hline MIG & 55.63 & & \\
\hline $\mathrm{KC}$ & 42.37 & & \\
\hline MCP-1 & 34.60 & & \\
\hline MIP- $1 \alpha$ & 34.22 & & \\
\hline IL-6 & 24.65 & M1 & STAT3 \\
\hline IL-1b & 24.07 & & \\
\hline MIP-1 $\beta$ & 21.75 & & \\
\hline $\mathrm{M}-\mathrm{CSF}$ & 19.41 & M2 & \\
\hline RANTES & 16.80 & & \\
\hline IL-12 (p70) & 15.52 & & STAT4 \\
\hline IL-12 (p40) & 14.63 & & STAT4 \\
\hline IL-10 & 10.11 & M2 & STAT3 \\
\hline IL-7 & 7.68 & & \\
\hline IL-2 & 7.36 & & STAT5 \\
\hline TNF- $\alpha$ & 6.80 & & \\
\hline IFN- $\gamma$ & 6.35 & M1 & STAT1 \\
\hline IL-5 & 5.64 & & \\
\hline IL-17 & 4.72 & & \\
\hline LIF & 2.98 & & STAT3 \\
\hline IL-3 & 2.94 & & \\
\hline VEGF & 2.38 & & \\
\hline IL-4 & 1.84 & M2 & STAT6 \\
\hline
\end{tabular}

to $\mathrm{SOCS} 3^{\mathrm{Al} / \mathrm{fl}}$ mice (Figure $\left.3 \mathrm{~A}\right)$. SOCS3 ${ }^{-/-}$mice also exhibited decreased tumor formation $(71 \% ; 10 / 14)$ when compared to SOCS3 $^{\text {ff/fl }}$ mice $(100 \% ; 15 / 15)$ (Figure $\left.3 \mathrm{~A}\right)$. The intracranial tumors from $\mathrm{SOCS}^{\mathrm{f} / \mathrm{fl}}$ and $\mathrm{SOCS}^{-/-}$mice appear histologically similar in size and morphology (Figure 3B; $1.25 \times$ and $10 \times$ ), and the numbers of mitotic figures and blood vessel density were quantified (Figure 3B; 40× and Supplementary Figure 2). Interestingly, at the time of death, tumors from the $\mathrm{SOCS}^{--}$mice displayed significantly increased mitotic figures and microvessel (MV) density compared to tumors from the SOCS3 $3^{\mathrm{fl} / \mathrm{fl}}$ mice, possibly due to overcoming resistance and escaping an immune response in the $\mathrm{SOCS3}^{-/-}$mice (Supplementary Figure 2).

The survival data suggest tumor growth is inhibited in mice with SOCS3 deletion in myeloid cells. Therefore, we evaluated the growth of intracranial tumors in real 
time by bioluminescent imaging (BLI). GL261 cells were labeled with firefly luciferase (GL261-Luc) and injected into the brains of $\mathrm{SOCS}^{\mathrm{fl} / \mathrm{fl}}$ and $\mathrm{SOCS}^{-/-}$mice. On days 5-9 post tumor injection, tumor volume was similar between $\mathrm{SOCS}^{\mathrm{f} / \mathrm{fl}}$ and $\mathrm{SOCS}^{-/-}$mice (Supplementary Figure $3 \mathrm{~A}$ and $3 \mathrm{~B}$ ). On days $13-16$ post tumor injection, $\mathrm{SOCS}^{-/}$ mice display decreased tumor volume, although not statistically significant, when compared to SOCS3 ${ }^{\mathrm{fl} / \mathrm{fl}}$ tumor volume (Supplementary Figure 3C and 3D). This suggests that the prolonged survival observed in the $\mathrm{SOCS}^{-/-}$mice is not exclusively due to inhibition of tumor volume, but alternative mechanisms including altered immune cell function within the tumors may be responsible for the prolonged survival.

\section{Numbers of infiltrating myeloid cells are similar between $\mathrm{SOCS3}^{\mathrm{f} / \mathrm{fl}}$ and $\mathrm{SOCS3}^{-/-}$tumor bearing mice}

Myeloid cells, which include monocytes, neutrophils and macrophages, along with resident microglia, are the largest population of infiltrating cells in GBM tumors [2]. Therefore, we sought to determine if the levels of infiltrating myeloid cells varied in intracranial tumors in SOCS3 $3^{\mathrm{f} / \mathrm{fl}}$ and $\mathrm{SOCS}^{-/-}$mice. GL261 cells were injected into the brains of $\mathrm{SOCS}^{\mathrm{f} / \mathrm{fl}}$ and $\mathrm{SOCS}^{-/}$mice. At death, brain sections were stained with IbaI to label infiltrating GAMs in the brains and tumors of the mice. Iba1 stains microglia in the normal brain as well as GAMs in the tumor [6]. Both $\mathrm{SOCS}^{\mathrm{fl} / \mathrm{fl}}$ and $\mathrm{SOCS}^{-/-}$mice have a robust infiltration of GAMs in the tumors (Figure 4). Morphologically, both $\mathrm{SOCS} 3^{\mathrm{f} / \mathrm{fl}}$ and $\mathrm{SOCS} 3^{--}$brain sections contain GAMs that appear amoeboid, or activated, in the tumor (left of the black dotted line) when compared to the ramified or resting microglia seen in the normal brain (right of the dotted line) (Figure 4, top and middle panels), which is comparable to what others have reported [17].

To more appropriately quantify the numbers of myeloid cells in tumors of the mice, flow cytometry was employed. GL261-Luc cells were injected into the brains of SOCS3 $3^{\mathrm{f} / \mathrm{fl}}$ and $\mathrm{SOCS}^{-/-}$mice. At day 15, all mice were euthanized to determine the levels of infiltrating GAMs in the brains/tumors of the mice. Mononuclear cells were isolated and stained with Abs to CD11b, Gr-1, F4/80 and CD45 and the percentage of macrophages $\left(\mathrm{CD} 11 \mathrm{~b}^{+} \mathrm{F} 4 / 80^{+}\right.$ CD45 $\left.{ }^{\text {hi }}\right)$, microglia $\left(\mathrm{CD} 11 \mathrm{~b}^{+} \mathrm{F} 4 / 80^{+} \mathrm{CD} 45^{\mathrm{mid}}\right)$, monocytes $\left(\mathrm{CD} 11 b^{\text {mid }} \mathrm{Gr}-1^{\text {mid }}\right)$, or neutrophils $\left(\mathrm{CD} 11 b^{\text {hi }} \mathrm{Gr}-1^{\text {hi }}\right)$, and were gated and quantified as previously described $[18,19]$. As shown in Figure 5, there was not a statistically significant difference in the number of infiltrating macrophages, microglia, monocytes or neutrophils between tumors from $\mathrm{SOCS}^{\mathrm{f} / \mathrm{fl}}$ and $\mathrm{SOCS}^{-/-}$mice.
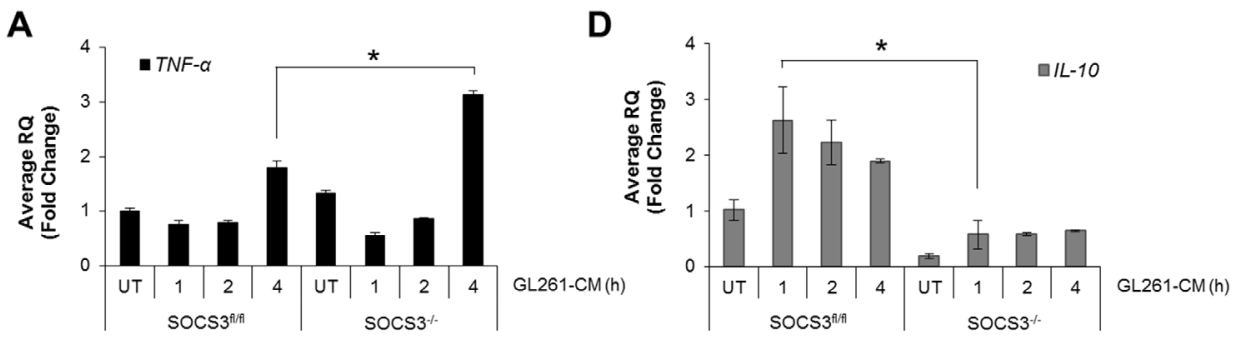

B
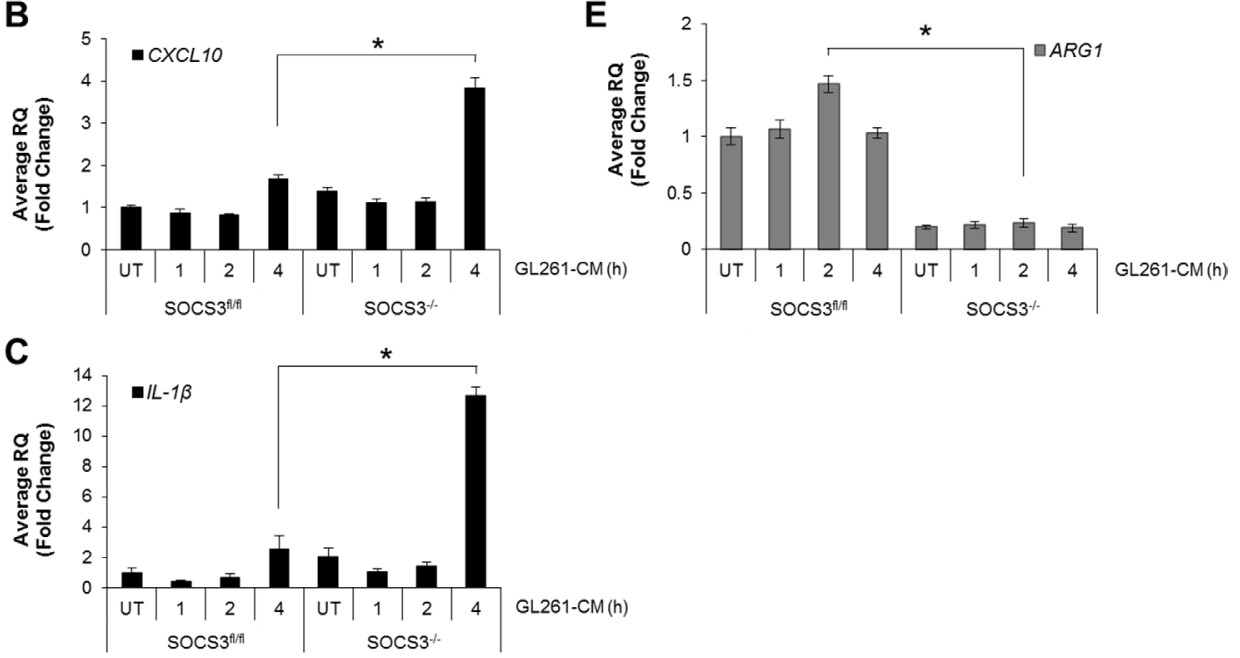

Figure 2: $\mathrm{SOCS3}^{-/-}$macrophages display enhanced M1 gene expression when exposed to GL261 conditioned medium. (A-E) SOCS3 $3^{\mathrm{f} / \mathrm{fl}}$ and $\mathrm{SOCS}^{-/-}$BMDM were harvested from the femurs of 7-8 week old mice and cultured in RPMI 1640 containing $10 \%$ FBS and $10 \mathrm{ng} / \mathrm{ml}$ murine M-CSF for 5-7 days to expand. Cells were plated and at $24 \mathrm{~h}$ treated with GL261 conditioned medium (50\% volume) for the indicated times. RNA was isolated, cDNA generated and qRT-PCR performed for the indicated genes. ${ }^{*} p<0.05$. Data are shown as mean \pm S.D. 


\section{Decreased infiltration of Arg1 $1^{+}$GAMs in intracranial tumors of $\mathrm{SOCS3}^{-/-}$mice}

Given that the absolute numbers of GAMs did not differ between $\mathrm{SOCS}^{\mathrm{f} / \mathrm{fl}}$ and $\mathrm{SOCS}^{-/-}$mice, we speculated there may be functional differences in the GAM population that are responsible for the prolonged survival. Therefore, we tested M1/M2 markers in GAMs in the in vivo intracranial model. GL261-Luc cells were injected into the brains of $\mathrm{SOCS}^{\mathrm{Atfl}}$ and $\mathrm{SOCS}^{-/-}$mice. At day 14 , all mice were euthanized to determine the levels of M1/ M2 GAMs in the brains/tumors of the mice. Mononuclear cells were isolated and stained with Abs to CD45, CD11b, Arg1, and iNOS and the percentage of M2 GAMs (CD45

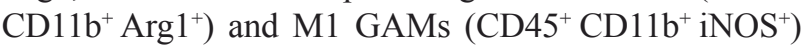
were gated and quantified. We found that tumors in the $\mathrm{SOCS}^{-/-}$mice contained significantly decreased numbers of $\mathrm{Arg}^{+}$(M2) GAMs compared to $\mathrm{SOCS}^{\mathrm{fl} / \mathrm{l}}$ mice, but no difference in the number of $\mathrm{iNOS}^{+}$(M1) GAMs (Figure 6A and 6B). However, there were no significant differences between the frequency of $\mathrm{Arg}^{+}$or $\mathrm{iNOS}^{+}$ GAMs in the tumors of $\mathrm{SOCS}^{\text {t/fll }}$ compared to $\mathrm{SOCS}^{-1-}$ mice (Figure 6C and 6D). Interestingly, we found that the $\mathrm{Arg}^{+}$cells in both $\mathrm{SOCS}^{\mathrm{t} / \mathrm{fl}}$ and $\mathrm{SOCS}^{-/-}$tumors were

A

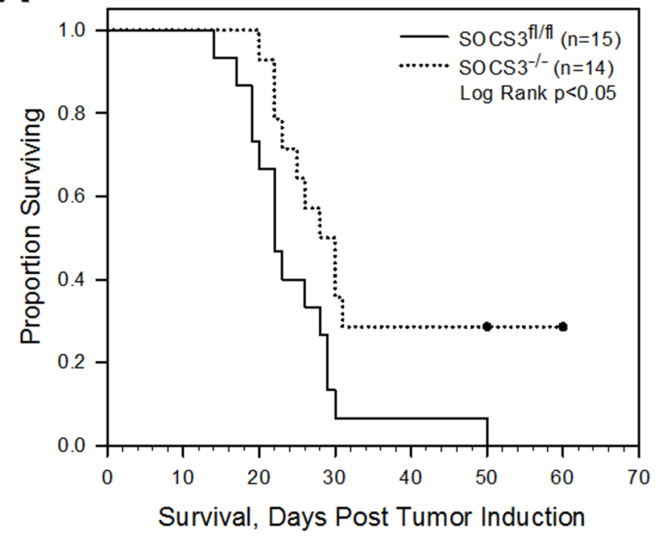

\begin{tabular}{l|l} 
Genotype & \% Tumor Formation
\end{tabular}

\begin{tabular}{l|l}
$\operatorname{SOCS}^{\text {fl/fl }}$ & $100 \%(15 / 15)$
\end{tabular}

SOCS3 $^{\text {/- }} \quad 71 \%(10 / 14)$

B
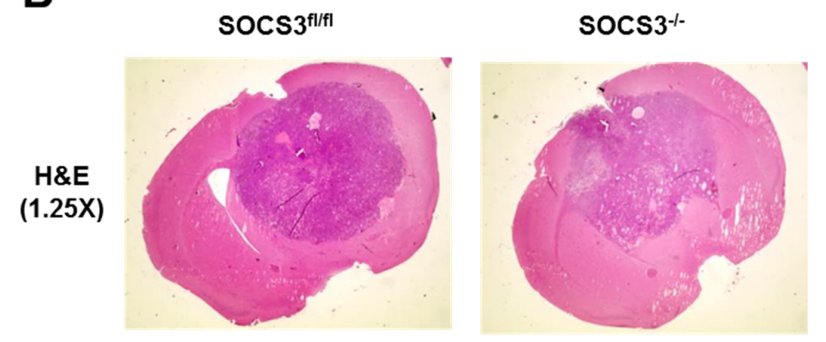

H\&E
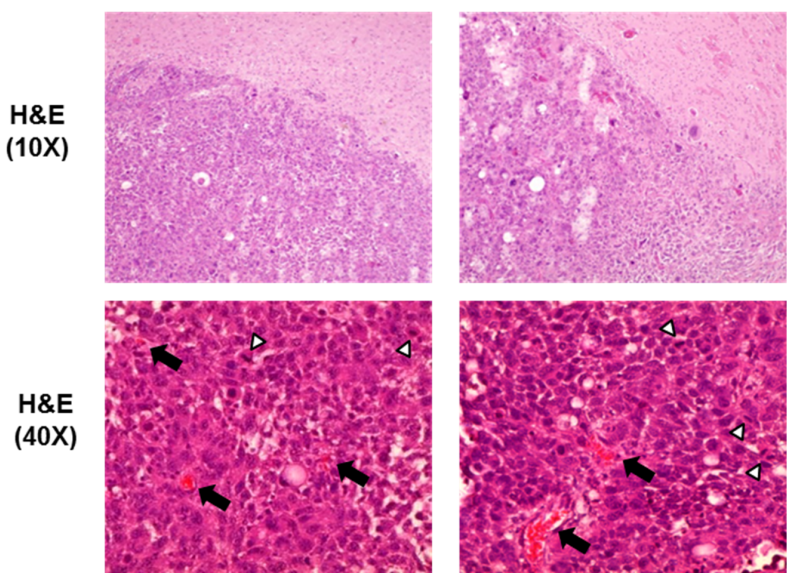

Figure 3: Deletion of SOCS3 in myeloid cells prolongs in vivo survival. (A) SOCS3 $3^{\mathrm{t} / \mathrm{fl}}$ and $\mathrm{SOCS} 3^{-/}$mice were injected intracranially with GL261 cells $\left(1 \times 10^{6}\right.$ cells $\left./ 5 \mu \mathrm{l}\right)$. Mice were monitored for survival and euthanized at moribund. Combination of two independent experiments are shown. $\log \operatorname{Rank} p<0.05$. (B) At death, (times varied as shown in survival curve) brains from SOCS3 ${ }^{\text {t/f }}$ and $\mathrm{SOCS3}^{--}$mice injected with GL261 cells were formalin fixed, paraffin embedded, sectioned and $\mathrm{H} \& \mathrm{E}$ stained. Representative images are shown from each group. Black arrows indicate blood vessels and white arrow heads indicate mitotic figures. 
also positive for iNOS, indicating that the M1/M2 status of the GAMs in our model is not mutually exclusive, and a mixed phenotype is observed (Figure 6E and 6F, upper right quandrant). Lastly, the expression level (MFI) of Arg1 in GAMs was significantly decreased in the tumors of the $\mathrm{SOCS}^{-/-}$mice compared to SOCS3 $3^{\mathrm{f} / \mathrm{fl}}$ mice (Figure 6G), but iNOS expression in GAMs did not reach statistical significance (Figure $6 \mathrm{H}$ ). Thus, in vivo SOCS3 deletion in myeloid cells results in decreased numbers of Arg $1^{+}$GAM infiltration as well as overall decreased $\mathrm{Arg} 1^{+}$expression in the tumors of $\mathrm{SOCS}^{-/-}$mice compared to $\mathrm{SOCS} 3^{\mathrm{f} / \mathrm{fl}}$ mice.

\section{Increased infiltration of $\mathrm{CD8}^{+} \mathrm{T}$-cells and reduced infiltration of Tregs in intracranial tumors of $\mathrm{SOCS3}^{-/-}$mice}

The presence of immunosuppressive Tregs is abundant in GBM tumors and corresponds to an inhibition of cytotoxic $\mathrm{CD}^{+}$T-cell function [20]. As GAMs are known to suppress anti-tumor T-cell mechanisms [4], we determined the levels of T-cell subsets in our model. GL261-Luc cells were injected into the brains of SOCS3 $3^{\mathrm{f} / \mathrm{fl}}$ and $\mathrm{SOCS}^{-/-}$mice. On days 13-21, to ensure similar tumor volumes as measured by BLI between experiments, mice were euthanized and numbers of infiltrating T-cells analyzed by flow cytometry. We found that $\mathrm{SOCS3}^{-1-}$ tumor bearing mice have significantly increased $\mathrm{CD}^{+}$ T-cell infiltration and significantly decreased Treg infiltration in the brains/tumors (Figure 7A-7B, 7D-7E). There were no differences in the percentage of $\mathrm{CD}^{+}$ T-cells in the mice (Figure 7C and 7D). This observation indicates that in addition to reduced numbers of M2 GAMs in $\mathrm{SOCS}^{-/-}$mice, an increased cytotoxic T-cell response may aid in overall survival.

\section{DISCUSSION}

In glioma, it is widely accepted that the most common infiltrating cells in the tumor are macrophages and microglia [21-23]. However, methods to label and

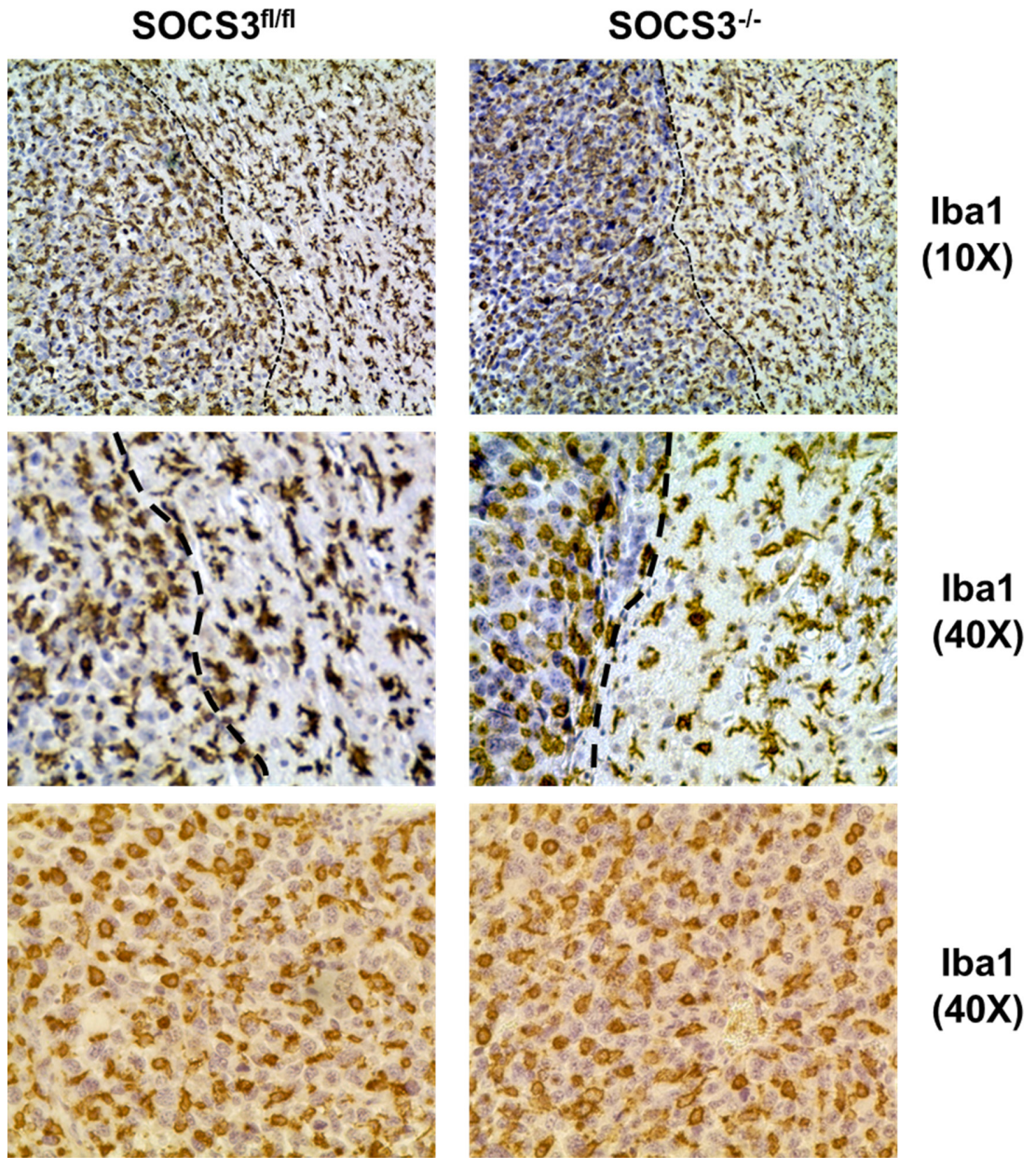

Figure 4: GAM infiltration and morphological activation is similar between SOCS3 ${ }^{\mathrm{fl} / \mathrm{fl}}$ and $\mathrm{SOCS3}^{-/-}$tumor bearing mice. SOCS3 $3^{\mathrm{f} / \mathrm{fl}}$ and $\mathrm{SOCS3}^{-/-}$mice were injected intracranially with GL261 cells $\left(1 \times 10^{6} \mathrm{cells} / 5 \mu \mathrm{l}\right)$. Mice were monitored for survival and euthanized at moribund. Brains were formalin fixed, paraffin embedded, sectioned and stained with Iba1. Representative images are shown from each group. Top and middle panels, $10 \times$ and $40 \times$ Ibal staining of brains with both tumor and normal brain shown. Black dotted line denotes border between tumor (left) and normal brain (right). Bottom panels, $40 \times$ Ibal staining of intracranial tumor section. 
distinguish microglia from peripheral macrophages (GAMs) are not as concise [21]. The most commonly used method to distinguish resident microglia versus infiltrating GAMs from the periphery is the expression of CD45, with microglia displaying mid to low CD45 expression and GAMs displaying high CD45 expression [23]. Using this method, we observed a much higher frequency of GAMs infiltrating the brains/tumors of both $\mathrm{SOCS}^{\mathrm{fl} / \mathrm{fl}}$ and $\mathrm{SOCS}^{-/}$ mice compared to resident microglia (Figure 5A-5C). Others have reported similar infiltration of peripheral GAMs in glioma tumors $[24,25]$. In order to evaluate the role of SOCS3/STAT3 in myeloid cells in our model, we employed the LysMCre conditional mouse model. Recently, reports have indicated that the LysMCre efficiency in microglia is less than 25\% [26-28]; thus, in our model, some expression of SOCS3 would be retained in microglia following the
A

B
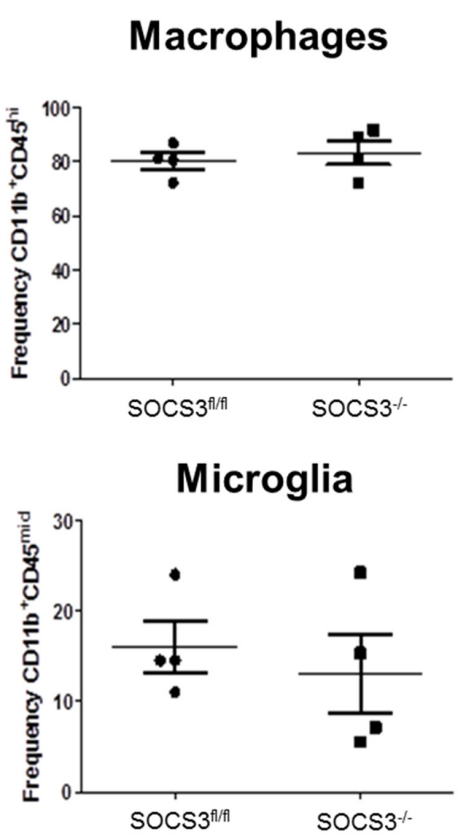

D

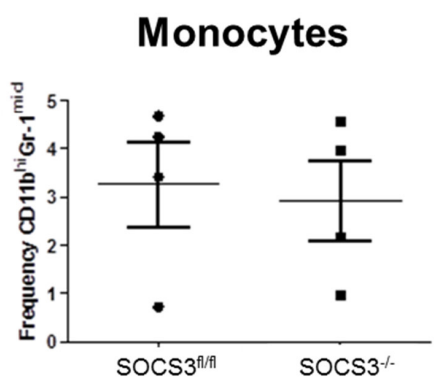

$\mathbf{E}$

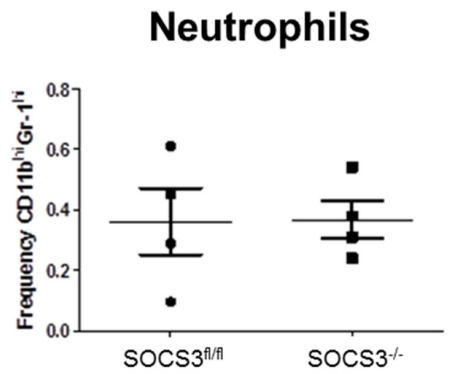

C

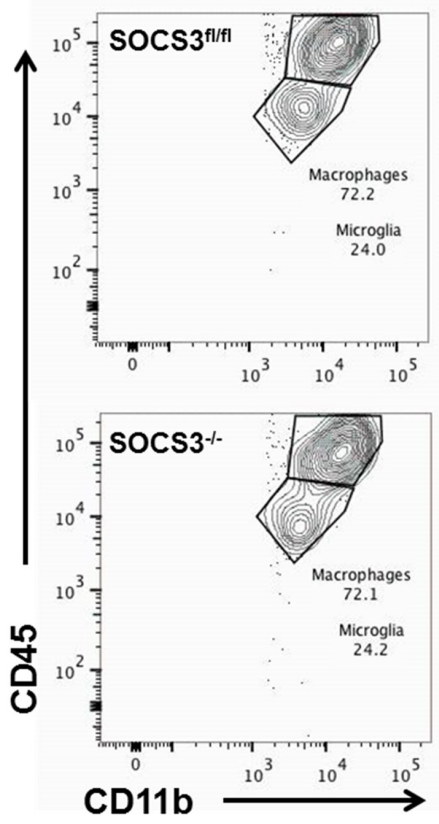

$\mathbf{F}$

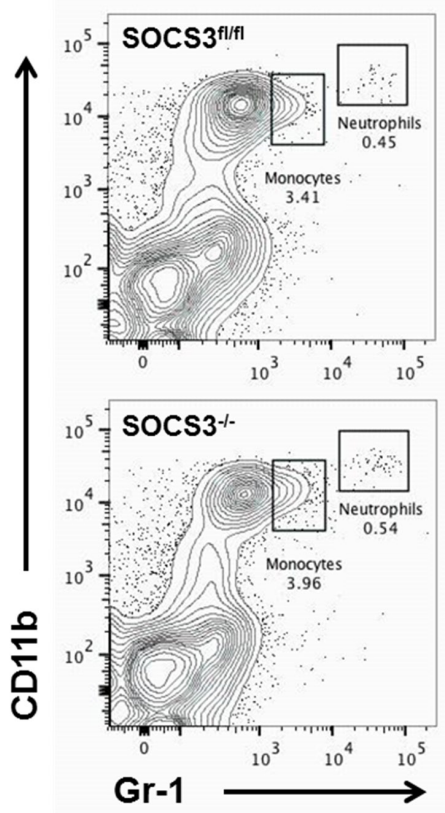

Figure 5: Loss of SOCS3 in myeloid cells does not affect the quantity of myeloid cell tumor infiltration. (A-F) SOCS3 ${ }^{\mathrm{f} / \mathrm{fl}}$ $(n=4)$ and $\mathrm{SOCS}^{-/-}(n=4)$ mice were injected intracranially with GL261 cells $\left(1 \times 10^{6}\right.$ cells $\left./ 5 \mu \mathrm{l}\right)$. Mice were euthanized on day 15 , and mononuclear cells were isolated from the brains/tumors and analyzed by flow cytometry for macrophages $\left(\mathrm{CD} 11 \mathrm{~b}^{+} \mathrm{F} 4 / 80^{+} \mathrm{CD} 45^{\mathrm{hi}}\right)$, microglia $\left(\mathrm{CD} 11 \mathrm{~b}^{+} \mathrm{F} 4 / 80^{+} \mathrm{CD} 45^{\mathrm{mid}}\right)$, monocytes $\left(\mathrm{CD} 11 \mathrm{~b}^{\text {mid }} \mathrm{Gr}-1^{\mathrm{mid}}\right)$, or neutrophils $\left(\mathrm{CD} 11 \mathrm{~b}^{\text {hi }} \mathrm{Gr}-\mathrm{1}^{\mathrm{hi}}\right)$, and were gated and quantified. Data are shown as mean \pm S.D. 
conditional deletion and theoretically still aide tumor growth. Regardless, we observed that loss of SOCS3 in the myeloid population produced a phenotype that significantly prolonged survival of mice bearing intracranial tumors (Figure $3 \mathrm{~A}$ ). The $\mathrm{SOCS}^{-/-}$mice also exhibited reduced tumor incidence (Figure 3A), indicating that the loss of SOCS3 in the myeloid cell population may aide in tumor rejection. However, the observation that there was no statistically significant difference in tumor volume could be explained by the role of microglia, as it has been shown that microglia aide in tumor invasion [29], which would be separate from the anti-tumor effects of the SOCS3 deficient GAMs in our model. Overall, the anti-tumor effects leading to prolonged survival in the $\mathrm{SOCS}^{-/-}$mice we observed can be attributed to GAMs, which have infiltrated from the periphery and are the major population of infiltrating cells.

To date, the role of JAK/STAT signaling in GBM macrophages remains relatively uncharacterized. For
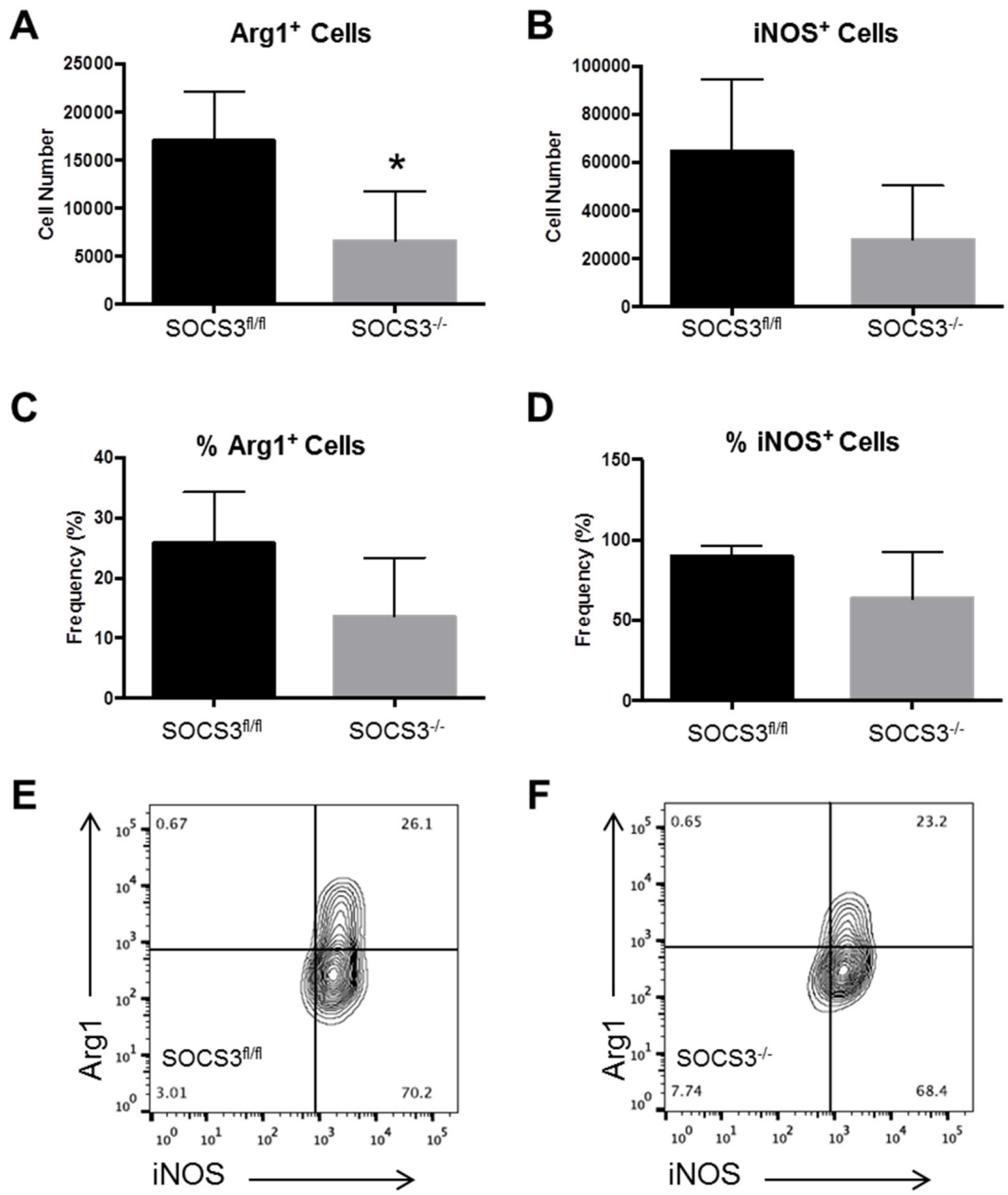

$\mathbf{F}$
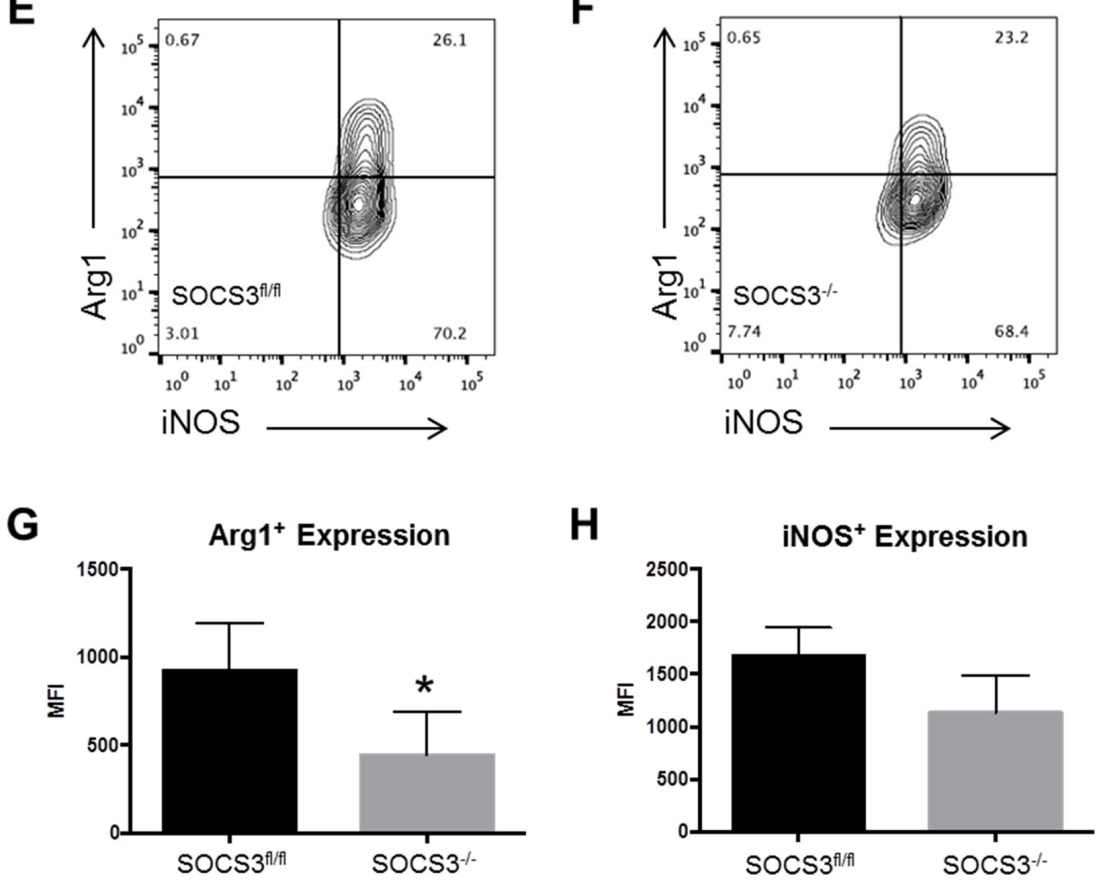

Figure 6: $\mathrm{SOCS3}^{--}$mice with intracranial tumors have diminished numbers of infiltrating Arg1 ${ }^{+} \mathrm{M}^{2}$ polarized cells compared to SOCS3 ${ }^{\mathrm{f} / \mathrm{fl}}$ mice. SOCS3 $3^{\mathrm{f} / \mathrm{fl}}$ mice $(n=4)$ and $\operatorname{SOCS}^{-/-}$mice $(n=4)$ were injected with GL261-Luc cells $\left(1 \times 10^{6}\right.$ cells $\left./ 5 \mu \mathrm{l}\right)$. Mice were euthanized on day 14, and mononuclear cells were isolated from the brains/tumors and analyzed by flow cytometry for Arg1

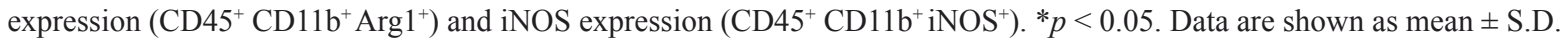


example, it has been postulated that STAT1 activation is associated with M1 polarization and STAT3 activation is associated with M2 polarization [23, 30]. In addition, Zhang et al. showed that intratumoral injection of STAT3 targeted siRNA promoted M1 activation [31]. Although there is evidence that STAT3 is activated in GAMs and may be responsible for the $\mathrm{M} 2$ phenotype, our data demonstrate that STAT3 also influences an M1 anti-tumor response. We found that BMDMs deficient for SOCS3 exhibited an enhanced STAT3 activation that led to increased expression of M1 proinflammatory cytokines in vitro. Furthermore, our in vivo data suggest that enhanced GAM STAT3 activation leads to decreased M2 GAM infiltration in tumors of SOCS3 ${ }^{\mathrm{f} / \mathrm{fl}}$ mice compared to $\mathrm{SOCS} 3^{-/-}$mice in vivo. Thus, the exact role and mechanisms of how macrophages can regulate GBM and how the JAK/STAT or other signaling pathways are utilized by these macrophages remains controversial.
Pro-inflammatory M1 macrophages are becoming an exciting therapeutic target in cancer because of their antitumor functional properties. Moreover, in patients with GBM, Zeiner et al., found that an M1 polarized immune milieu is associated with prolonged survival [32]. Thus, discovering ways to promote M1 macrophage polarization in tumors is being examined as a relevant therapeutic avenue. Recent reports indicate that amphotericin administration or CSF-1R inhibition promotes M1 activity in GBM [33, 34]. Additionally, Lisi et al., found that mTOR kinase inhibitors promoted glioma activated microglia to express an M1 phenotype [35]. In a rat model of glioma, dopamine treatment inhibited tumor growth through reprogramming of M2-polarized macrophages to an M1 phenotype [36]. In other cancer models, various agents including low dose irradiation and phosphatidylserine antibody treatment resulted in promoting a pro-inflammatory M1 phenotype in GAMs that decreased tumor growth $[37,38]$. Thus, it is
A

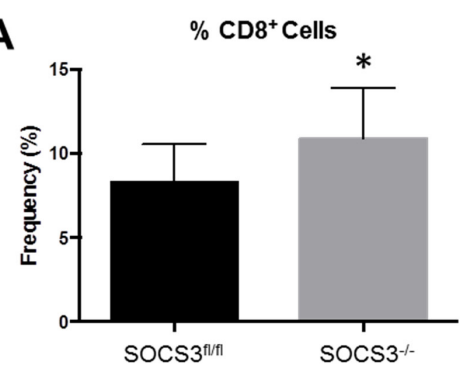

B

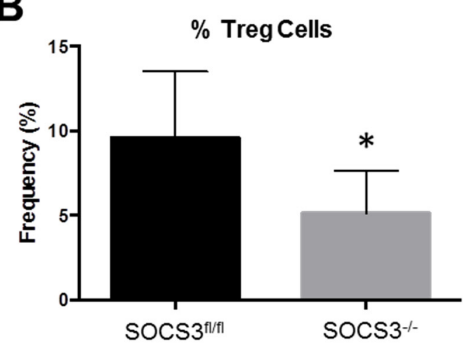

C

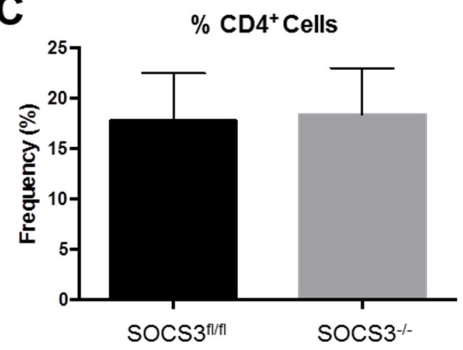

$\operatorname{SOCS} 3^{\text {fl/fl }}$

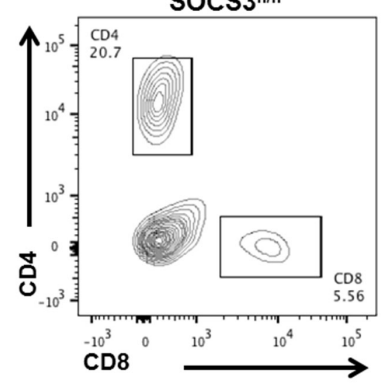

$\operatorname{SOCS} 3^{\text {fl/fl }}$

E

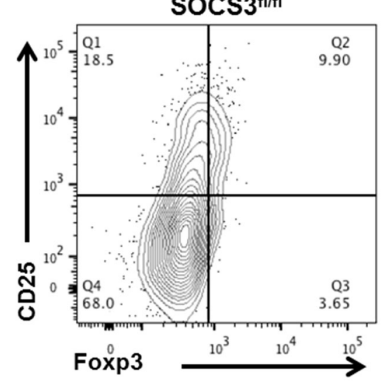

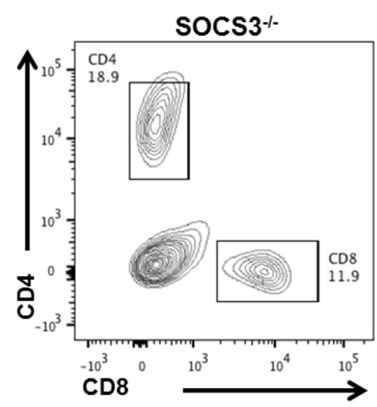

SOCS3-

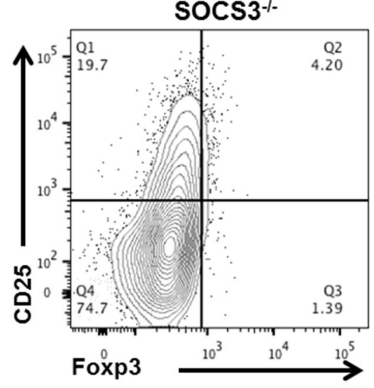

Figure 7: Loss of SOCS3 in myeloid cells results in increased $\mathrm{CD8}^{+} \mathrm{T}$-cell and decreased Treg infiltration in tumors. (A and C) $\operatorname{SOCS}^{\mathrm{t} / / \mathrm{l}}(n=11)$ and $\operatorname{SOCS}^{-/-}(n=10)$ mice were injected intracranially with GL261-Luc cells $\left(1 \times 10^{6}\right.$ cells/5 $\left.\mu 1\right)$. Mice were euthanized on days 13-14 for analysis of infiltrating $\mathrm{CD}^{+} \mathrm{T}$-cells $\left(\mathrm{CD} 8^{+}\right)$and $\mathrm{CD} 4^{+} \mathrm{T}$-cells $\left(\mathrm{CD} 4^{+}\right)$in the brains and quantified by flow cytometry. Combination of two experiments are shown. ${ }^{*} p<0.05$. (B) $\operatorname{SOCS}^{\mathrm{A} / \mathrm{fl}}(n=9)$ and $\mathrm{SOCS}^{-/-}(n=9)$ mice were injected intracranially with GL261-Luc cells $\left(1 \times 10^{6}\right.$ cells $\left./ 5 \mu \mathrm{l}\right)$. Mice were euthanized on days 13 or 21 for analysis of infiltrating Tregs $\left(\mathrm{CD} 4^{+} \mathrm{CD} 25^{+} \mathrm{Foxp} 3^{+}\right)$. Combination of two experiments are shown. ${ }^{*} p<0.05$. Data are shown as mean \pm S.D. (D and E) Representative histograms of CD4 ${ }^{+}, \mathrm{CD} 8^{+}$ and Treg populations are shown for each genotype. 
becoming increasingly obvious that promoting anti-tumor macrophages is beneficial, but the mechanisms of how to maintain the M1 anti-tumor phenotype in vivo remains largely unknown.

The terminology and characterization of M1/M2 macrophages is also becoming increasingly complicated in the context of cancer. Recent studies demonstrated that in several models of cancer including GBM, GAMs exhibit a mixed M1/M2 phenotype, depending on the time and stage of disease. For example, when freshly isolated GAMs from human GBM patients were compared to M1 and M2 polarized human macrophages, it was observed that GAMs from GBM patients expressed both M1 and M2 markers simultaneously [6]. More recently, Szulzewsky et al., performed an extensive microarray analysis of GAMs from two murine models of glioma and compared to existing M1/M2 databases [8]. They observed that GAMs from both murine glioma models display a gene expression pattern that only partly overlapped with specific M1 and M2 subsets, and that the GAM expression profile can be considered a unique glioma-associated phenotype, independent of traditional macrophage subsets. When evaluating the evolution of GAM function during the course of disease, it was reported that GAMs display a M2 phenotype early, but switch to a mixed M1/M2 phenotype later in a rat model of glioma [7]. Furthermore, it has been demonstrated that in the GL261 model of glioma, GAMs are closely similar to myeloid-derived suppressor cells (MDSC) in function and also exhibit a mixed M1/M2 phenotype [5]. The role of MDSCs, an immunosuppressive myeloid progenitor cell population [39], is not detailed in this model. Because the majority of the myeloid cells infiltrating the brains/tumors of mice were Gr-1- (Figure 5D-5F), and MDSCs are largely $\mathrm{Gr}-1^{+}$, we did not examine their role.

In our model, we found that the overall total number of Arg $1^{+}$GAMs were significantly decreased in tumors of $\mathrm{SOCS}^{-/-}$mice compared to SOCS3 ${ }^{\mathrm{fl} / \mathrm{fl}}$ mice. Interestingly, we observed that $\mathrm{Arg}^{+} \mathrm{GAMs}$ were almost exclusively $\mathrm{iNOS}^{+}$as well in tumors of both $\mathrm{SOCS}^{\mathrm{f} / \mathrm{fl}}$ and $\mathrm{SOCS}^{-/-}$ mice. This indicates that similar to what others have reported, GAMs in our model display a mixed M1/M2 phenotype. On the other hand, we observed that the overall expression, i.e., amount of Arg1 per cell, was decreased in tumors of $\mathrm{SOCS}^{--}$compared to $\mathrm{SOCS}^{\mathrm{fl} / \mathrm{fl}}$ mice. Thus, deletion of SOCS3 in myeloid cells resulted in decreased total numbers of Arg $1^{+}$GAMs as well as decreased overall expression in GAMs. The exact role of arginase expression in GAM function has yet to be fully appreciated and will be examined in the future.

Glioma tumors express tumor-associated antigens that should be detectable to immune clearance $[40,41]$. However, due to the immunosuppressive environment, these tumors are allowed to continue growth and proliferation. In cancer, it is widely accepted that the predominance of Tregs in the tumor help aid in immunosuppression [41].
Expression of forkhead transcription factor 3 (Foxp3) and suppression of T-cell mediated immunity are exclusive characteristics of Tregs [42]. In GBM, Tregs suppress $\mathrm{CD}^{+}$and $\mathrm{CD}^{+}$T-cell activation and are considered a major contributor to tumor progression [41]. In this study, we found that $\mathrm{SOCS}^{-/-}$tumors exhibited decreased Treg infiltrates as well as a reciprocal increase in $\mathrm{CD}^{+} \mathrm{T}$-cell infiltrates. This is an exciting observation, and indicates that therapeutic manipulation of GAMs can enhance T-cell mediated anti-tumor immune responses in GBM.

In conclusion, the use of targeted small molecule inhibitors in GBM has been unsuccessful in the clinical setting, and alternative methods of combating tumor growth are being considered [1]. This report describes a novel mouse glioma model where the infiltrating GAMs promote an anti-tumor response. This model is a genetic model (conditional deletion of SOCS3 in myeloid cells) and therefore does not rely on small molecule inhibitors or other treatments that could yield toxicities or offtarget effects to induce the therapeutic response. This allows for a definitive method of understanding the role of macrophages in GBM, as well as future experiments determining the therapeutic potential of GAMs when combined with additional anti-cancer therapies.

\section{MATERIALS AND METHODS}

\section{Ethics statement}

Investigation has been conducted in accordance with the ethical standards and according to the Declaration of Helsinki and according to national and international guidelines and has been approved by the authors' institutional review board.

\section{Cells and reagents}

Murine glioma cells (GL261 and GL261-Luc) were a generous gift from Dr. G. Yancey Gillespie (UAB Brain Tumor Model Core Facility) and were grown in DMEM/ F12 10\% FBS, L-glutamine, and Pen/Strep as described [43]. Bone marrow derived macrophages (BMDM) were isolated and cultured as previously described [14]. For immunoblotting experiments, antibodies for phosphoSTAT3 (Y705) and total STAT3 were purchased from Cell Signaling (9131; 79D7), and GAPDH from AbCam (ab8245). For IHC, rabbit anti-Ibal was purchased from Wako (019-19741), rabbit anti-vWf from Millipore (AB7356) and rabbit anti-Ki67 from Abcam (AB15580). For flow cytometry experiments, antibodies for CD45 (30F11), CD11b (M1/70), Gr-1 (RB6-8C5), F4/80 (BM8), CD4 (GK1.5), CD8 (53-6.7), Foxp3 (MF-14), CD25 (PC61) were purchased from BioLegend, iNOS (CXNFT) from eBioscience, and Arg1 (IC5868A) from R \& D Systems [19, 44]. The mouse cytokine/chemokine multiplex ELISA assay was purchased from EMD Millipore (MPXMCyto-70K). 


\section{Generation of GL261 conditioned medium}

GL261 cells (80\% confluent) were grown in DMEM/F12 media without serum for $24 \mathrm{~h}$. Supernatants were collected for use in BMDM and Multiplex ELISA experiments.

\section{Immunoblotting}

BMDMs were plated in 6-well plates and treated with GCM for the indicated times. Protein levels were quantified and equal amounts of protein were loaded on SDS-PAGE acrylamide gels and immunoblotted as described [45]. Densitometry was performed and the levels of phosphorylated STAT3 normalized to total STAT3 levels. Analyses are presented as \% increase over corresponding hourly time points between the $\mathrm{SOCS}^{\mathrm{t} / \mathrm{fl}}$ and $\mathrm{SOCS}^{-/-}$ BMDMs.

\section{qRT-PCR}

BMDMs were plated in 6 well plates and treated with GCM for the indicated times. RNA was isolated using TriZol and cDNA generated as described [45]. cDNA was run on the Applied Biosystems platform to obtain quantitative CT values. Data are presented as Average RQ (Fold Increase) for each gene normalized to the housekeeping gene HPRT. The following Taqman probe/primer sets were purchased from Applied Biosystems: SOCS3 (Mm01249143_g1), TNF- $a(\mathrm{Mm} 00443258 \mathrm{~m} 1)$, CXCL10 (Mm99999072_m1), IL-1 $\beta$ (Mm01336189_m1), IL-10 (Mm00439614_m1), ARG1 (Mm00475988_m1), and HPRT (Mm00446968_m1).

\section{Multiplex ELISA}

GL261 cells were grown in DMEM/F12 media without serum for $24 \mathrm{~h}$. Supernatants were collected and run on the multiplex ELISA assay according to the manufacturer's protocol and as described [46].

\section{Mice}

All experiments with mice were approved by the Institutional Animal Care and Use Committee of the University of Alabama at Birmingham. SOCS3 conditional knockout $\left(\mathrm{SOCS}^{--}\right)$mice were generated by breeding $\mathrm{SOCS}^{\mathrm{A} / \mathrm{fl}}$ mice with mice expressing Cre recombinase under the control of the LysM promoter, in which the conditional SOCS3 allele is therefore excised in myeloid cells [13].

\section{Intracranial injections}

Six- to 8-week-old mice were used for intracranial experiments. Mice were injected with GL261 or GL261Luc cells as previously described [43, 47]. For survival studies, mice were monitored for signs of tumor burden and euthanized at moribund. Survival times were recorded and brains/tumors removed for analyses. For flow cytometry experiments, mice were euthanized on the indicated days and brains/tumors removed for analyses.

\section{Immunohistochemical staining}

Mice were injected with GL261 cells and at moribund, mice were euthanized and brains removed, formalin fixed, and paraffin embedded. Sections $(8 \mu \mathrm{m})$ were stained with hematoxylin and eosin as described [18]. For IbaI and $v W f$ staining, sections $(8 \mu \mathrm{m})$ were deparaffinized followed by antigen retrieval, and incubated with primary antibodies overnight at $4^{\circ} \mathrm{C}$, Next, sections were incubated with SuperPicture secondary antibody for $1 \mathrm{~h}$, staining detected with $\mathrm{DAB}$, and nuclei counterstained with hematoxylin. Images were obtained using the EVOS XL Core Cell Imaging System, utilizing 1.25×, 10×, and $40 \times$ objective lenses in addition to the $10 \times$ eyepiece objective lens.

\section{Bioluminescent imaging}

For the indicated experiments, mice were intracranially injected with GL261-Luc cells and tumor volume obtained using the Xenogen IVIS-100 Luminescent Imager. Mice were injected (i.p.) with luciferin and anesthetized for imaging. Region of interest (ROI) values were obtained using Living Image Software (Perkin Elmer) and plotted as average total photon counts per group. Representative images of mice are shown for each group and time point.

\section{Flow cytometry}

Mice were intracranially injected with GL261Luc cells, and tumor growth monitored by BLI. On the indicated days, mice were anesthetized, perfused with PBS and brains, including the tumor, were removed, collagenase digested and passed through a $100 \mu \mathrm{m}$ cell strainer. Mononuclear cells were then obtained by a percoll gradient. Specifically, macrophages $\left(\mathrm{CD}_{11} \mathrm{~b}^{+} \mathrm{F} 4 / 80^{+} \mathrm{CD} 45^{\text {hi }}\right)$, microglia $\left(\mathrm{CD} 11 \mathrm{~b}^{+} \mathrm{F} 4 / 80^{+} \mathrm{CD} 45^{\text {mid }}\right)$, monocytes $\left(\mathrm{CD} 11 \mathrm{~b}^{\text {mid }}\right.$ Gr- ${ }^{\text {mid }}$ ), and neutrophils (CD11 b $\left.{ }^{\text {hi }} \mathrm{Gr}-1^{\text {hi }}\right)$ were gated and analyzed for myeloid populations. For T-cell populations, $\mathrm{CD} 8^{+}$T-cells $\left(\mathrm{CD} 8^{+}\right)$, Tregs $\left(\mathrm{CD} 4^{+} \mathrm{CD} 25^{+}\right.$Foxp3 $\left.^{+}\right)$and $\mathrm{CD}^{+} \mathrm{T}$-cells $\left(\mathrm{CD}^{+}\right)$were gated and analyzed. For Arg1 and iNOS populations, GAMs were gated and analyzed for $\left(\mathrm{CD}_{4} 5^{+} \mathrm{CD} 11 \mathrm{~b}^{+} \mathrm{Arg} 1^{+}\right)$or $\left(\mathrm{CD} 45^{+} \mathrm{CD}_{11 b^{+}} \mathrm{iNOS}^{+}\right)$. Samples were run on the LSRII FACS Caliber and data analyzed by FlowJo software and displayed as total cell numbers, frequency of the population (\%), or mean fluorescence intensity (MFI) as previously described [13].

\section{Statistical analyses}

Sigma-Plot statistical analysis software was used for the statistical analyses of this manuscript. Specifically, 
statistical significance $(p<0.05)$ was determined using Student $t$-test for comparison of 2 values, ANOVA analysis on appropriate multivariable analyses and the Log Rank test for Kaplan-Meier survival curves.

\section{ACKNOWLEDGMENTS}

The authors of this manuscript wish to acknowledge Dr. Yancey Gillespie and Catherine Langford for the GL261-Luc cells through the UAB Small Animal Models Core Facility (NIH \#P01 A071933), Dr. Terry Lewis with assistance performing IHC through the UAB Neuroscience Molecular Detection Core (NIH \#P30 NS47466), Dr. John Mountz and Enid Keyser for assistance with flow cytometry analyses through the UAB Comprehensive Flow Cytometry Core (NIH \#P30 AR048311), Dr. Kurt Zinn, Sharon Samuel and Marie Warren with in vivo BLI through the UAB Small Animal Imaging Core (DOD \#W81XWH-12-1-0356 and NIH/DHHS \#2P30CA013148), Dr. Chad Steele (UAB) for assistance with multiplex ELISA, Sara Gibson and Zhaoqi Yan for technical assistance with FlowJo, and Phyllis Walker and Tom Fox for technical assistance with the BMDM preparations.

\section{GRANT SUPPORT}

Funding for this work was provided by grants from the National Institutes of Health (R01CA158534 and R01CA194414 to E.N.B. and T32NS048039 to A.L.R. and S.C.F.); American Brain Tumor Association Discovery Grant (B.C.M.); UAB William E. Cash Jr. Memorial Fund in Neuro-Oncology Research (B.C.M); UAB Faculty Development Grant (B.C.M.); and UAB's Cancer Research Experiences for Students (CaRES) Program, 5R25CA76023, funded by the National Cancer Institute (M.P.M.).

\section{CONFLICTS OF INTEREST}

The authors declare no financial or competing conflicts of interests.

\section{REFERENCES}

1. Dunn GP, Rinne ML, Wykosky J, Genovese G, Quayle SN, Dunn IF, Agarwalla PK, Chheda MG, Campos B, Wang A, Brennan C, Ligon KL, Furnari F, et al. Emerging insights into the molecular and cellular basis of glioblastoma. Genes Dev. 2012; 26:756-784.

2. Li W, Graeber MB. The molecular profile of microglia under the influence of glioma. Neuro-Oncol. 2012; 14:958-978.

3. Benveniste EN, Liu Y, McFarland BC, Qin H. Involvement of the janus kinase/signal transducer and activator of transcription signaling pathway in multiple sclerosis and the animal model of experimental autoimmune encephalomyelitis. J Interferon Cytokine Res. 2014; 34:577-588.
4. Biswas SK, Allavena P, Mantovani A. Tumor-associated macrophages: functional diversity, clinical significance, and open questions. Semin Immunopathol. 2013; 35:585-600.

5. Umemura N, Saio M, Suwa T, Kitoh Y, Bai J, Nonaka K, Ouyang GF, Okada M, Balazs M, Adany R, Shibata T, Takami T. Tumor-infiltrating myeloid-derived suppressor cells are pleiotropic-inflamed monocytes/macrophages that bear M1- and M2-type characteristics. J Leukoc Biol. 2008; 83:1136-1144.

6. Hattermann K, Sebens S, Helm O, Schmitt AD, Mentlein R, Mehdorn HM, Held-Feindt J. Chemokine expression profile of freshly isolated human glioblastoma-associated macrophages/microglia. Oncol Rep. 2014; 32:270-276.

7. Lisi L, Stigliano E, Lauriola L, Navarra P, Dello Russo C. Proinflammatory-activated glioma cells induce a switch in microglial polarization and activation status, from a predominant M2b phenotype to a mixture of $\mathrm{M} 1$ and $\mathrm{M} 2 \mathrm{a} / \mathrm{B}$ polarized cells. ASN Neuro. 2014; 6:171-183.

8. Szulzewsky F, Pelz A, Feng X, Synowitz M, Markovic D, Langmann T, Holtman IR, Wang X, Eggen BJ, Boddeke HW, Hambardzumyan D, Wolf SA, Kettenmann H. Gliomaassociated microglia/macrophages display an expression profile different from M1 and M2 polarization and highly express Gpnmb and Spp1. PLoS One. 2015; 10:e0116644.

9. Sielska M, Przanowski P, Wylot B, Gabrusiewicz K, Maleszewska M, Kijewska M, Zawadzka M, Kucharska J, Vinnakota K, Kettenmann H, Kotulska K, Grajkowska W, Kaminska B. Distinct roles of CSF family cytokines in macrophage infiltration and activation in glioma progression and injury response. J Pathol. 2013; 230:310-321.

10. O'Shea JJ, Plenge R. JAK and STAT signaling molecules in immunoregulation and immune-mediated disease. Immunity. 2012; 36:542-550.

11. Yu H, Pardoll D, Jove R. STATs in cancer inflammation and immunity: a leading role for STAT3. Nat Rev Cancer. 2009; 9:798-809.

12. Miklossy G, Hilliard TS, Turkson J. Therapeutic modulators of STAT signalling for human diseases. Nat Rev Drug Discov. 2013; 12:611-629.

13. Qin H, Yeh WI, De Sarno P, Holdbrooks AT, Liu Y, Muldowney MT, Reynolds SL, Yanagisawa LL, Fox TH, 3rd, Park K, Harrington LE, Raman C, Benveniste EN. Signal transducer and activator of transcription-3/suppressor of cytokine signaling-3 (STAT3/SOCS3) axis in myeloid cells regulates neuroinflammation. Proc Natl Acad of Sci. 2012; 109:5004-5009.

14. Qin H, Holdbrooks AT, Liu Y, Reynolds SL, Yanagisawa LL, Benveniste EN. SOCS3 deficiency promotes M1 macrophage polarization and inflammation. J Immunol. 2012; 189: 3439-3448.

15. Yasukawa H, Ohishi M, Mori H, Murakami M, Chinen T, Aki D, Hanada T, Takeda K, Akira S, Hoshijima M, Hirano T, Chien KR, Yoshimura A. IL-6 induces an anti-inflammatory response in the absence of SOCS3 in macrophages. Nat Immunol. 2003; 4:551-556. 
16. Oh T, Fakurnejad S, Sayegh ET, Clark AJ, Ivan ME, Sun MZ, Safaee M, Bloch O, James CD, Parsa AT. Immunocompetent murine models for the study of glioblastoma immunotherapy. J Transl Med. 2014; 12:107.

17. Gabrusiewicz K, Ellert-Miklaszewska A, Lipko M, Sielska M, Frankowska M, Kaminska B. Characteristics of the alternative phenotype of microglia/macrophages and its modulation in experimental gliomas. PLoS One. 2011; 6:e23902.

18. Yu H, Liu Y, McFarland BC, Deshane JS, Hurst DR, Ponnazhagan S, Benveniste EN, Qin H. SOCS3 deficiency in myeloid cells promotes tumor development: Involvement of STAT3 activation and myeloid-derived suppressor cells. Cancer Immunol Res. 2015; 3:727-740.

19. Liu Y, Holdbrooks AT, Meares GP, Buckley JA, Benveniste EN, Qin H. Preferential recruitment of neutrophils into the cerebellum and brainstem contributes to the atypical experimental autoimmune encephalomyelitis phenotype. J Immunol. 2015; 195:841-852.

20. Jackson CM, Lim M, Drake CG. Immunotherapy for brain cancer: recent progress and future promise. Clin Cancer Res. 2014; 20:3651-3659.

21. Zhou W, Bao S. Reciprocal supportive interplay between glioblastoma and tumor-associated macrophages. Cancers. 2014; 6:723-740.

22. da Fonseca AC, Badie B. Microglia and macrophages in malignant gliomas: recent discoveries and implications for promising therapies. Clin Dev Immunol. 2013; 2013:264124.

23. Wei J, Gabrusiewicz K, Heimberger A. The controversial role of microglia in malignant gliomas. Clin Dev Immunol. 2013; 2013:285246.

24. Feng X, Szulzewsky F, Yerevanian A, Chen Z, Heinzmann D, Rasmussen RD, Alvarez-Garcia V, Kim Y, Wang B, Tamagno I, Zhou H, Li X, Kettenmann H, et al. Loss of CX3CR1 increases accumulation of inflammatory monocytes and promotes gliomagenesis. Oncotarget. 2015; 6:15077-15094. doi: 10.18632/oncotarget.3730.

25. Chae M, Peterson TE, Balgeman A, Chen S, Zhang L, Renner DN, Johnson AJ, Parney IF. Increasing gliomaassociated monocytes leads to increased intratumoral and systemic myeloid-derived suppressor cells in a murine model. Neuro-Oncol. 2014; 17:978-991.

26. Goldmann T, Wieghofer P, Muller PF, Wolf Y, Varol D, Yona S, Brendecke SM, Kierdorf K, Staszewski O, Datta M, Luedde T, Heikenwalder M, Jung S, et al. A new type of microglia gene targeting shows TAK1 to be pivotal in CNS autoimmune inflammation. Nat Neurosci. 2013; 16: 1618-1626.

27. Wang J, Wegener JE, Huang TW, Sripathy S, De Jesus-Cortes H, Xu P, Tran S, Knobbe W, Leko V, Britt J, Starwalt R, McDaniel L, Ward CS, et al. Wild-type microglia do not reverse pathology in mouse models of Rett syndrome. Nature. 2015; 521:E1-4.
28. Wieghofer P, Knobeloch KP, Prinz M. Genetic targeting of microglia. Glia. 2014; 63:1-22.

29. Sliwa M, Markovic D, Gabrusiewicz K, Synowitz M, Glass R, Zawadzka M, Wesolowska A, Kettenmann H, Kaminska B. The invasion promoting effect of microglia on glioblastoma cells is inhibited by cyclosporin A. Brain. 2006; 130:476-489.

30. Wu A, Wei J, Kong LY, Wang Y, Priebe W, Qiao W, Sawaya R, Heimberger AB. Glioma cancer stem cells induce immunosuppressive macrophages/microglia. Neuro-Oncol. 2010; 12:1113-1125.

31. Zhang L, Alizadeh D, Van Handel M, Kortylewski M, Yu H, Badie B. Stat3 inhibition activates tumor macrophages and abrogates glioma growth in mice. Glia. 2009; 57:1458-1467.

32. Zeiner PS, Preusse C, Blank AE, Zachskorn C, Baumgarten P, Caspary L, Braczynski AK, Weissenberger J, Bratzke H, Reiss S, Pennartz S, Winkelmann R, Senft C, et al. MIF receptor $\mathrm{CD} 74$ is restricted to microglia/macrophages, associated with a M1-polarized immune milieu and prolonged patient survival in gliomas. Brain Pathol. 2014; 25:491-504.

33. Sarkar S, Doring A, Zemp FJ, Silva C, Lun X, Wang X, Kelly J, Hader W, Hamilton M, Mercier P, Dunn JF, Kinniburgh D, van Rooijen N, et al. Therapeutic activation of macrophages and microglia to suppress brain tumorinitiating cells. Nat Neurosci. 2014; 17:46-55.

34. Pyonteck SM, Akkari L, Schuhmacher AJ, Bowman RL, Sevenich L, Quail DF, Olson OC, Quick ML, Huse JT, Teijeiro V, Setty M, Leslie CS, Oei Y, et al. CSF-1R inhibition alters macrophage polarization and blocks glioma progression. Nat Med. 2013; 19:1264-1272.

35. Lisi L, Laudati E, Navarra P, Dello Russo C. The mTOR kinase inhibitors polarize glioma-activated microglia to express a M1 phenotype. J Neuroinflamm. 2014; 11:125.

36. Qin T, Wang C, Chen X, Duan C, Zhang X, Zhang J, Chai H, Tang T, Chen H, Yue J, Li Y, Yang J. Dopamine induces growth inhibition and vascular normalization through reprogramming M2-polarized macrophages in rat C6 glioma. Toxicol Appl Pharmacol. 2015; 286:112-123.

37. Klug F, Prakash H, Huber PE, Seibel T, Bender N, Halama N, Pfirschke C, Voss RH, Timke C, Umansky L, Klapproth K, Schakel K, Garbi N, et al. Low-dose irradiation programs macrophage differentiation to an $\mathrm{iNOS}(+) / \mathrm{M} 1$ phenotype that orchestrates effective $\mathrm{T}$ cell immunotherapy. Cancer Cell. 2013; 24:589-602.

38. Yin Y, Huang X, Lynn KD, Thorpe PE. Phosphatidylserinetargeting antibody induces M1 macrophage polarization and promotes myeloid-derived suppressor cell differentiation. Cancer Immunol Res. 2014; 1:256-268.

39. Gabrilovich DI, Ostrand-Rosenberg S, Bronte V. Coordinated regulation of myeloid cells by tumours. Nat Rev Immunol. 2012; 12:253-268.

40. Rolle CE, Sengupta S, Lesniak MS. Mechanisms of immune evasion by gliomas. Adv Exp Med and Biol. 2012; 746:53-76. 
41. Wainwright DA, Nigam P, Thaci B, Dey M, Lesniak MS. Recent developments on immunotherapy for brain cancer. Expert Opin Emerg Drugs. 2012; 17:181-202.

42. Fontenot JD, Gavin MA, Rudensky AY. Foxp3 programs the development and function of CD4+CD25+ regulatory $\mathrm{T}$ cells. Nat Immunol. 2003; 4:330-336.

43. McFarland BC, Ma JY, Langford CP, Gillespie GY, Yu H, Zheng Y, Nozell SE, Huszar D, Benveniste EN. Therapeutic potential of AZD1480 for the treatment of human glioblastoma. Mol Cancer Ther. 2011; 10:2384-2393.

44. Liu Y, Holdbrooks AT, De Sarno P, Rowse AL, Yanagisawa LL, McFarland BC, Harrington LE, Raman C, Sabbaj S, Benveniste EN, Qin H. Therapeutic efficacy of suppressing the Jak/STAT pathway in multiple models of experimental autoimmune encephalomyelitis. J Immunol. 2014; 192:59-72.
45. Rajbhandari R, McFarland BC, Patel A, Gerigk M, Gray GK, Fehling SC, Bredel M, Berbari NF, Kim H, Marks MP, Meares GP, Sinha T, Chuang J, et al. Loss of tumor suppressive microRNA-31 enhances TRADD/NF-kappaB signaling in glioblastoma. Oncotarget. 2015; 6:17805-17816. doi: 10.18632/oncotarget.4596.

46. Meares GP, Liu Y, Rajbhandari R, Qin H, Nozell SE, Mobley JA, Corbett JA, Benveniste EN. PERK-dependent activation of JAK1 and STAT3 contributes to endoplasmic reticulum stress-induced inflammation. Mol Cell Biol. 2014; 34:3911-3925.

47. McFarland BC, Hong SW, Rajbhandari R, Twitty GB, Jr., Gray GK, Yu H, Benveniste EN, Nozell SE. NF-kappaBinduced IL-6 ensures STAT3 activation and tumor aggressiveness in glioblastoma. PLoS One. 2013; 8:e78728. 